\title{
Studies to show that with podophyllotoxin the early replicative stages of herpes simplex virus type 1 depend upon functional cytoplasmic microtubules
}

\author{
T. R. HAMMONDS, S. P. DENYER*, D. E. JACKSON and W. L. IRVING $\dagger$
}

Department of Pharmaceutical Sciences, University of Nottingham, University Park, Nottingham NG7 2RD, *Department of Pharmacy, University of Brighton, Moulsecoomb, Brighton BN2 4GJ and †Department of Microbiology, Queens Medical Centre, Nottingham NG7 2UH

\begin{abstract}
The antiviral activity of podophyllotoxin against herpes simplex type 1 virus (HSV-1) grown in Vero cells was studied by a simple microtitration assay. Antiviral effects were induced at similar concentrations as direct cellular toxicity, as characterised by a time-dependent loss of cell monolayer. Podophyllotoxin-mediated toxicity arises from cytoplasmic microtubular, and hence cytoskeletal, decay. Some degree of selectivity was seen for inhibition of virus replication over direct cellular toxicity. Podophyllotoxin acted against an early viral process, as an antiviral effect was still seen if drug was removed $2 \mathrm{~h}$ after infection. Similar effects were seen with colchicine, a classical tubulin-binding compound, but not with bromovinyldeoxyuridine. Podophyllotoxin was capable of inducing a cytoprotective effect in Vero cells, as pre-treatment of cells abrogated virus growth for up to $90 \mathrm{~min}$ after removal of drug. This is coincident with the repolymerisation of cellular microtubules and re-formation of the cytoskeleton. We conclude that HSV-1 relies upon a functional cellular cytoskeleton for efficient completion of an early replicative event. Such a process may be the transport of viral material to the nucleus or inhibition of the formation of intranuclear viral 'replication factories', bodies containing cytoskeletal fragments constructed after viral infection.
\end{abstract}

\section{Introduction}

Microtubules are structural cellular components which, when combined with other structures such as actin, myosin and intermediate filaments, form a fine network of protein polymers known as the cytoskeleton [1]. The dimeric protein, tubulin, creates the body of the microtubule by polymerising in the presence of GTP to form a series of linked protofilaments [2]. In vivo, a continual exchange of polymerised tubulin with tubulin from the cellular pool creates a state of dynamic instability [3-5]. The rate at which dynamically unstable microtubules polymerise and depolymerise depends upon the availability of tubulin and GTP. The process of dynamic instability is further complicated by cellular factors affecting microtubule stability [6]. Cellular microtubules are classified on the basis of their position and their relative dynamic instabilities [7].

Received 23 Oct. 1995; revised version accepted 23 Jan. 1996.

Corresponding author: Dr W. L. Irving.
Three main types of microtubules are observed: mitotic spindle microtubules - which have an observed half-time of tubulin incorporation of around $20 \mathrm{~s}$ [8]; cytoplasmic microtubules - with a half-time of incorporation of 10-15 min; and stable cytoplasmic microtubules which show very slow exchange, being stable for $\geqslant 2 \mathrm{~h}$ [7]. By exhibiting varying degrees of stability the microtubules provide the resting cell with a constantly updating structural and transport system and, during cell division, the microtubules become a highly organised multifunctional system essential for efficient replication.

Following infection with herpes simplex virus type 1 (HSV-1), viral immediate early and late capsid proteins bind to structural cellular components, including microtubules, and remain associated with such structures during all stages of viral replication [9-11]. Microtubular structures at the nucleus may act as a biological 'anchor' for viral proteins to allow processes such as mRNA transcription, DNA replication and DNA packaging prior to virion release [12]. The association of capsid proteins and microtubules has also led to suggestions that the naked herpesvirus 
particle is transported to the nucleus via the cytoskeleton [13].

Compounds that depolymerise microtubules are commonly tubulin-binding agents [14]. Podophyllotoxin inhibits tubulin incorporation into microtubules, and at high concentrations interacts directly with the microtubule [15]. Podophyllotoxin has antiviral activity against the DNA viruses HSV-1 and murine cytomegalovirus but not against the RNA-containing Sindbis virus [16-19]. The antiviral activity of podophyllotoxin is thought to be mediated at an early stage of replication [19]. The tubulin binding agents colchicine and vincristine also exhibit antiviral activity in vitro [20-23]. Each report suggests that activity is in some way mediated by disruption of microtubules, possibly by disruption of cellular transport processes essential for virion assembly at the cell membrane. In contrast to these data, tubulin binding agents have also been shown to increase polyoma virus-induced cell transformations [24] and many viruses, including HSV-1, actively disrupt the cellular cytoskeleton, presumably to aid their own replicative processes $[13,25]$.

Therefore, the relationship between inhibition of microtubule polymerisation and inhibition of virus replication is unclear and little is known of the mechanism by which these compounds exert an antiviral effect. In this study a simple microtitration assay was used to investigate the effects of podophyllotoxin on the growth of HSV-1 in Vero cells and on the resting and replicating processes of Vero cells alone. Further experiments were then performed to elucidate the stage of viral replication inhibited by this tubulin-binding compound.

\section{Materials and methods}

\section{Drugs, cells and viruses}

Podophyllotoxin was obtained by direct isolation from plant material [26]. Colchicine was purchased from Sigma, bromovinyldeoxyuridine (BVDU) was a gift from $\mathrm{Mr} \mathrm{M}$. Hawkins, Department of Virology, Queens Medical Centre, Nottingham. Compounds for assay were dissolved in dimethyl sulphoxide to $1 \mathrm{mg}$ / $\mathrm{ml}$ and stored at $-20^{\circ} \mathrm{C}$. Drug solutions were diluted in maintenance medium under aseptic conditions immediately before use.

Green monkey kidney (Vero) cells were grown and maintained as monolayers at $37^{\circ} \mathrm{C}$ in 199 medium (Gibco) containing newborn calf serum at $10 \%$ (growth medium, GM) or 1\% (maintenance medium, MM). Cells were passaged to produce an initial cell suspension [27] which was then used to seed microtitration plates for antiviral or toxicity studies. All assays were performed with 96-well flat-bottomed microtitration plates (Falcon or Costar). This allowed for 12 sets of eight replicates/assay as described below. Wells were seeded with Vero cells in $100 \mu 1$ of GM and incubated overnight in closed polypropylene containers. Once cells were confluent, GM was removed from the wells and each monolayer was covered with a final overlay of $160 \mu \mathrm{l}$ of MM. Unless otherwise stated, plates of this nature were used in each of the assays described below.

HSV-1 strain SC9 was a gift from Dr G. Halliburton, University of Leeds. The initial suspension was propagated in a $125-\mathrm{cm}^{2}$ cell-culture flask containing a monolayer of confluent Vero cells in GM. After culture for 3 days, at which time the virus-induced cytopathic effect (CPE) was almost $100 \%$, supernate from the flask was cleared of cellular debris by centrifugation in a bench centrifuge and stored in $100-200 \mu \mathrm{l}$ volumes in cryotube freezing vials at $-80^{\circ} \mathrm{C}$ until required. The tissue culture infectious dose (TCID50) of this culture supernate was determined by inoculating Vero cells with serial 10-fold dilutions and observing the presence or absence of CPE 7 days later.

\section{Crystal violet assay}

Monolayer quality was measured by a simple crystal violet (CV) assay. Plates were dipped into a tank of formaldehyde $10 \% \mathrm{v} / \mathrm{v}$ in phosphate-buffered saline and left for $15 \mathrm{~min}$ to fix cells and inactivate any virus present. Excess formaldehyde was removed by rinsing with water and plates were immediately immersed into a tank of crystal violet (BDH Chemicals Ltd) $0.025 \% \mathrm{w} / \mathrm{v}$ in ethanol $5 \% \mathrm{v} / \mathrm{v}$ for $10 \mathrm{~min}$. Unbound stain was removed by repeated washing with water and excess water was drained away on to paper towels. Stain that remained bound to monolayers was re-dissolved into $50 \mu \mathrm{l}$ of pure ethanol (spectroscopic grade) added to the wells and the absorbance value at $570 \mathrm{~nm}$ for each well was determined immediately (Dynatech MR580 ELISA reader) as a measure of monolayer quality. This method of measuring monolayer damage gave similar values for cell survival as those obtained by a standard MTT formezan-based assay [28] on identically treated cell monolayers.

\section{Assay of the antiviral activity and direct toxicity of podophyllotoxin}

Drug-containing MM $(20 \mu \mathrm{l})$ was added to Vero cells in freshly prepared microtitration plates to give serial 10 -fold dilutions. Virus stock suspension was added in MM $(20 \mu \mathrm{l})$ to a final titre of $c .1 \times 10^{3}$ TCID50. The final volume in each well was then made up to $200 \mu \mathrm{l}$ with MM. Plates were incubated for 3 days without removal of medium and the remaining monolayer was analysed by $\mathrm{CV}$ assay. Antiviral activity was measured as the percentage inhibition of monolayer destruction 
in wells with drug and virus added when compared to both virus-infected and drug-treated control wells. This was calculated by the following equation:

protection against viral effects $(\%)$

$$
=100(T-V) /(D-V)
$$

where measured absorbances in the $\mathrm{CV}$ assay were: $\mathrm{T}$, wells with drug and virus; V, wells with virus only; D, wells with drug only. Toxicity was measured as the percentage of viable monolayer detected in wells with drug only compared to untreated control wells.

\section{Assay of the cytostatic activity of podophyllotoxin}

Plates were seeded with $90 \mu \mathrm{l}$ of a 1 in 3 dilution of freshly passaged Vero cells in GM so as to give $c$. $40 \%$ cellular coverage of the microtitration wells at the beginning of the experiment. Compounds were added in $10 \mu \mathrm{l}$ volumes as a $10 \times$ concentrate in GM. Plates were incubated under standard conditions for 2 days and in this time $90-100 \%$ confluency was attained in control wells, as checked by microscopy. Monolayers were then analysed by the CV assay. Cytostatic activity was defined as occurring when the amount of monolayer detected in each well remained at $40 \%$ of the positive control value.

\section{Short contact antiviral assay}

Virus suspension $(20 \mu \mathrm{l})$ and drug solutions $(20 \mu \mathrm{l})$ were added to appropriate wells to a final viral titre five times that in the antiviral assay described above. All well volumes were then increased to $200 \mu \mathrm{l}$ with MM. After incubation for $2 \mathrm{~h}$ all media were removed. Wells were rinsed with $50 \mu \mathrm{l}$ of $\mathrm{MM}$ before a final overlay of $200 \mu \mathrm{l}$ of MM was added. Plates were incubated for 3 days under standard conditions and analysed for monolayer quantity by the CV assay.

\section{Cell pre-treatment assay}

The final overlay in a microtitration plate was increased to $180 \mu \mathrm{l}$ of $\mathrm{MM}$ and $20 \mu \mathrm{l}$ of a solution containing $50 \mu \mathrm{M}$ podophyllotoxin was added to appropriate wells. This plate was incubated under standard conditions for $4 \mathrm{~h}$ and all media were then removed and replaced by a wash of $50 \mu \mathrm{l}$ of $\mathrm{MM}$. This was removed after $1 \mathrm{~min}$ and replaced with an overlay of $180 \mu \mathrm{l}$ of MM. Virus was then added at set times after drug removal and to control wells at 0 and $120 \mathrm{~min}$. Cells were incubated for 3 days and analysed by the CV assay. The dual viral control was performed to standardise any differences in viral growth occurring due to the different times of inoculation. The percentage of the monolayer protected from viral effects was calculated by the equation shown in the assay for antiviral effects.

\section{Results}

Effects of podophyllotoxin on HSV-1 growth, Vero cell survival and cellular replication

Podophyllotoxin induced antiviral activity at $50 \mathrm{nM}$, (Fig. la), a 10-fold higher concentration than it induced cytostatic activity (5 nM, Fig. 1b) and hence was not a truly selective antiviral agent. However, direct cellular toxicity and antiviral effects occurred at similar concentrations (50 nM, Fig. $1 \mathrm{a}$ and c). Complete protection against monolayer damage induced by viral infection was seen at 500 and $5000 \mathrm{nM}$ podophyllotoxin. These concentrations caused only a $40 \%$ loss of the resting monolayer (Fig. la and c), indicating a degree of selectivity for viral replication over resting cellular functions. Podophyllotoxin concentrations up to 100 -fold above that which first induced direct toxicity gave rise to only similar, relatively small losses in the cell sheet (Fig. 1c).

The loss of stationary monolayer due to direct toxicity was closely linked to the time of exposure to podophyllotoxin (Fig. 2). With $5000 \mathrm{nM}$ podophyllotoxin as an example, no damage was seen after exposure for $2 \mathrm{~h}$ followed by drug removal and immediate CV assay, whereas $30 \%$ cell sheet loss was seen after incubation for 3 days with drug and around $50 \%$ loss after 6 days. The effects on stationary cells were fully reversible, as re-growth following drug treatment for 3 days occurred after removal of drug and replacement by drug-free growth medium (Fig. 2).

\section{Assays involving variable drug-virus contact times}

To determine whether the presence of podophyllotoxin throughout the incubation period of the assay was necessary for antiviral effects, it was tested alongside colchicine (another tubulin-binding agent) and BVDU (an antiviral agent that acts via inhibition of DNA polymerase [29]), in assays involving short- and long-term drug-cell contact times (Fig. 3). The two tubulin-binding agents showed significant activity against virus replication at the concentrations tested in both assays. Total inhibition of viral growth was obtained and, as compounds were only present for $2 \mathrm{~h}$ in this short contact assay, there was no significant toxicity to the stationary cell monolayer (Fig. 2). Similar antiviral effects were not seen with BVDU as the enzyme systems inhibited by this compound are not active during the first $2 \mathrm{~h}$ after virus infection. However, BVDU did give protection against virus when present in a long contact assay at a concentration identical to that used in the short contact assay.

The effect of treating cells with podophyllotoxin before HSV-1 infection was studied in the pretreatment assay (Fig. 4). Monolayer destruction due 
a

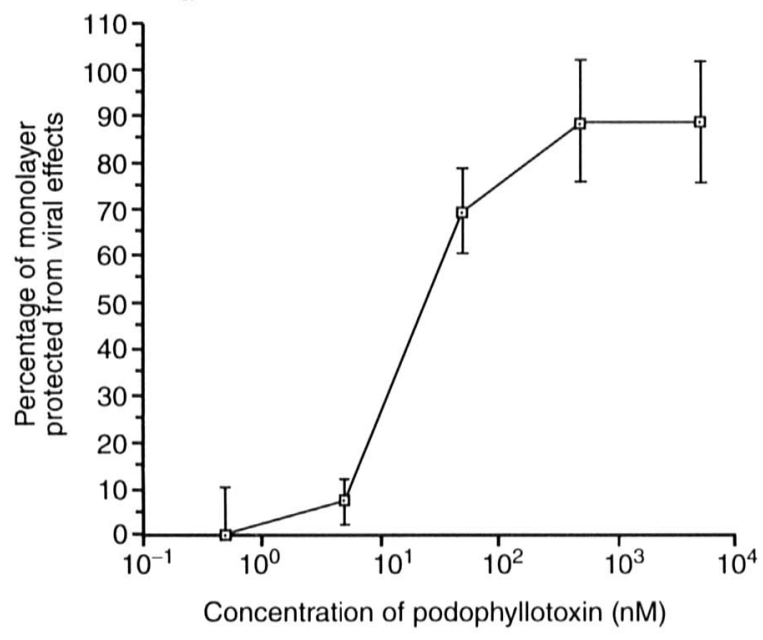

C
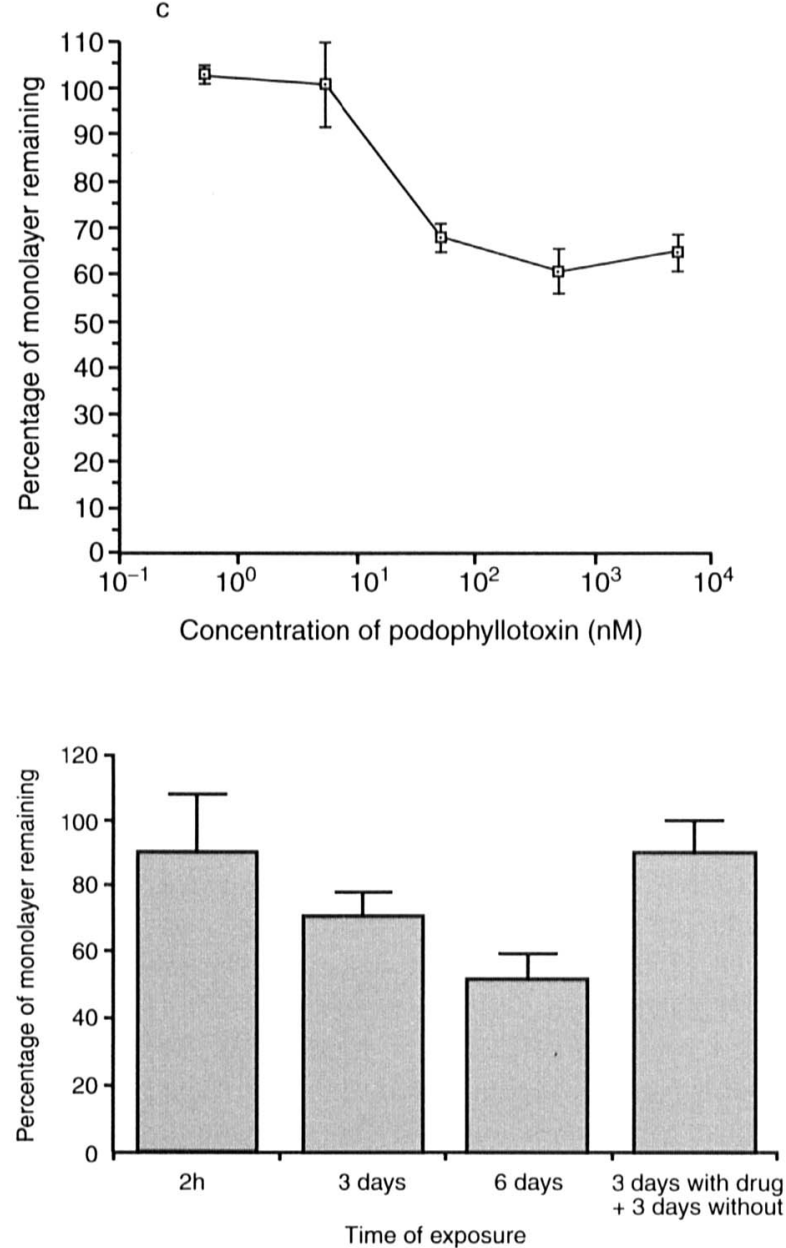

Fig. 2. Time-dependent nature of podophyllotoxin toxicity to stationary Vero cell monolayers. Results are shown as the average of eight replicates; bars represent $1 \mathrm{SD}$. Cell monolayers were incubated with $5000 \mathrm{nM}$ podophyllotoxin for the times indicated and assayed for monolayer quality by the $\mathrm{CV}$ method. The percentage toxicity was calculated by comparison with untreated controls assayed simultaneously.

to viral growth was not seen in those cells infected up to $30 \mathrm{~min}$ after drug removal, and only a small amount of monolayer loss was seen in cells infected 45 and $60 \mathrm{~min}$ after drug removal. Significant viral b

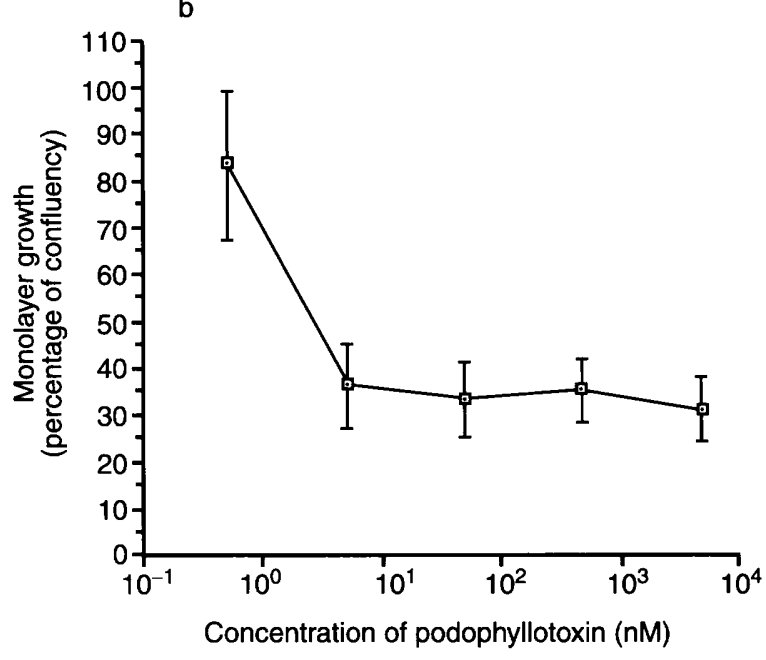

Fig. 1 a. Antiviral activity of podophyllotoxin. Confluent monolayers were incubated for 3 days in the presence of drug or virus, or both. Data are presented as the percentage of monolayer protected from virus-induced damage. b. Cytostatic activity of podophyllotoxin. Seeded wells were incubated with drug present. Cytostatic activity was measured by comparing the growth of drug-treated cells with that of untreated control cells after 2 days. Basal seeding level was approximately $40 \%$ of the level achieved by the confluent control. c. Direct cellular toxicity of podophyllotoxin. Confluent monolayers were incubated in the presence of drug for 3 days. Toxicity was measured as the percentage of treated monolayer measured when compared to untreated cells. Monolayer survival assessed by the CV assay; each point is the average of eight individual experiments; bars represent $1 \mathrm{SD}$.

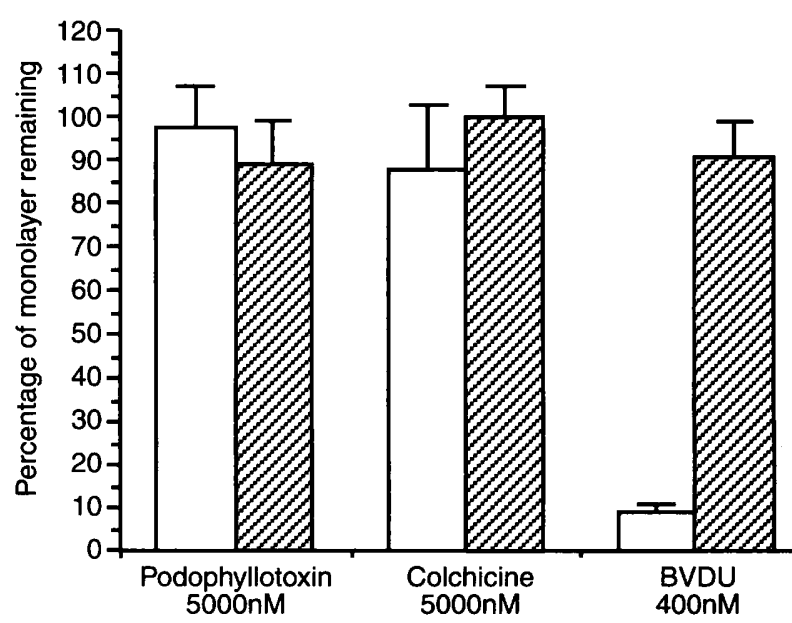

Fig. 3. Short ( $2 \mathrm{~h} ; \square)$ and long ( 3 days; $\square$ ) contact assay data for selected compounds against HSV-1. In both assays, monolayer survival was assessed by $\mathrm{CV}$ assay after a total incubation of 3 days. Data are shown as the average of eight replicates; bars represent $1 \mathrm{SD}$.

growth was seen in those cells infected 90 min after removal of podophyllotoxin and at $120 \mathrm{~min}$ after drug removal the virus grew as extensively as in control monolayers. 


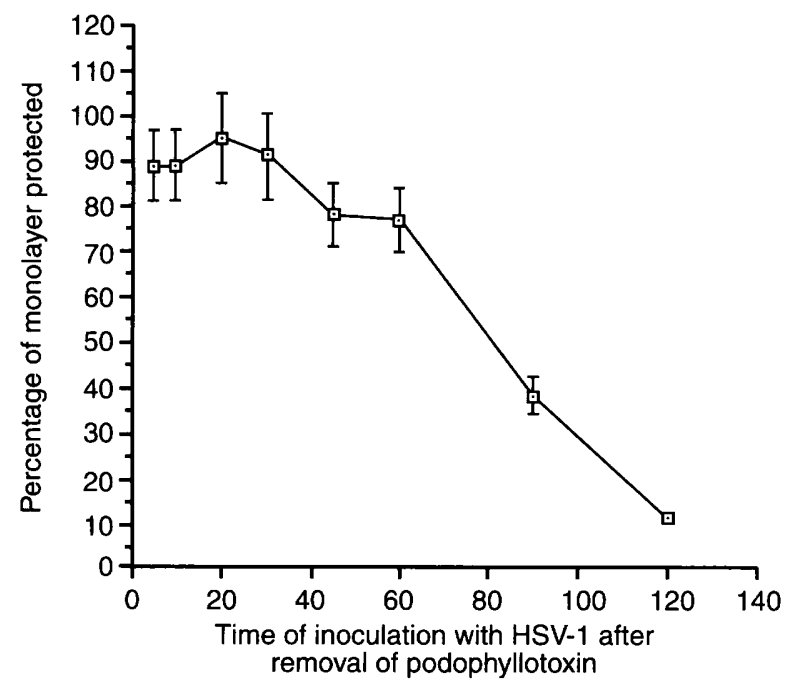

Fig. 4. Effect of the pre-treatment of Vero cells with podophyllotoxin on their ability to host HSV-1 growth. Cells were incubated with $5000 \mathrm{nM}$ podophyllotoxin for $4 \mathrm{~h}$, washed and inoculated with virus at set time intervals. The values for antiviral effects evident after 3 days culture were calculated from the equation given in Materials and methods and give the percentage survival of cells compared to standardised virally infected and drug-treated controls. Each point is the average of eight replicates; bars represent $1 \mathrm{SD}$.

\section{Discussion}

This study provides evidence for the involvement of microtubules in the early replication stages of HSV-1. It demonstrated that podophyllotoxin inhibits HSV-1 replication in stationary monolayers, and by the application of multiple concentrations and replicates showed that the antiviral and direct toxicity effects are distinct from the cytostatic effect of the drug. At low concentrations, podophyllotoxin inhibits the formation of only the most unstable of microtubules [15], i.e., those of the mitotic spindle $[4,6]$, leaving the more stable cytoplasmic microtubules relatively unaffected. At these concentrations cytostasis is seen (Fig. 1b). At higher concentrations of podophyllotoxin the cellular microtubules are unable to function efficiently and consequently direct toxicity to resting cells is seen (Fig. 1c). This accounts for the difference in cytostatic and toxic activities of this compound. We suggest that the loss of cytoplasmic microtubules is not in itself a cytotoxic event, rather it leads to the gradual degeneration of the cell. These effects were fully reversible upon removal of the drug (Fig. 2). Hence, the loss of stationary cells seemed to be mediated by a time-dependent cellular event or events which were initiated by the addition of a critical or supra-critical concentration of podophyllotoxin. The changes brought about by the drug not only inflicted a slow death upon the cell but appeared to alter its biochemistry in such a way that rendered viral replication impossible. The antiviral effect of podophyllotoxin was seen at similar concentrations to direct toxicity. This indicates that viral replication depends upon similarly stable microtubular or asso- ciated structures as does the viability of the resting cell.

The antiviral effect could also be induced when podophyllotoxin was present for only the first $2 \mathrm{~h}$ of HSV-1 replication (Fig. 3), precluding all but the earliest of viral replication processes from the list of possible biological targets. The antiviral compound BVDU showed no activity in the short contact assay, compared to effective antiviral activity at similar concentrations in the long contact assay. This compound acts by inhibiting enzymes involved in viral DNA replication and hence this short contact assay was selective for viral processes occurring before this replicative stage. The short contact assay also supported the involvement of tubulin as a target site of action, as colchicine, a classical tubulin-binding agent, showed potent antiviral activity after contact for only $2 \mathrm{~h}$. In HSV- 1 replication the first replication nuclei are found at $4 \mathrm{~h}$ after infection of receptive hosts. Therefore, adsorption, penetration, uncoating, immediate early protein synthesis and the beginnings of nuclear inclusion body synthesis would have occurred within $2 \mathrm{~h}$ [27]. Therefore, one or more of these early stages of HSV-1 infection depend upon microtubules.

The case for microtubular involvement in mediating these antiviral effects was further supported by the effect of pre-treatment of Vero cells prior to virus infection (Fig. 4). Vero cell monolayers were overlaid with $5000 \mathrm{~nm}$ podophyllotoxin for $4 \mathrm{~h}$ to depolymerise the cellular microtubules. After removal of drugcontaining medium, the reversible nature of the podophyllotoxin-tubulin complex dictated that microtubules would slowly re-form within the cell until an intact cytoskeleton was re-established. The timescale of the recovery of the cells to a state where viral growth was possible was close to what would be expected from published values concerning tubulin polymerisation and podophyllotoxin-tubulin interactions. The half-life of the tubulin-podophyllotoxin complex is c. $45 \mathrm{~min}$ [30] and growth of microtubules in vitro is complete in $10-25 \mathrm{~min}$ [31]. Thus, a value of $90 \mathrm{~min}$ for cytoskeletal recovery is not inconsistent with these data. Hence, we conclude that it is the restructuring of the cellular microtubules which precedes the ability of these cells to host HSV-1 replication.

Of the events in HSV-1 replication thought to involve microtubules, the transport of an infecting virus particle or the restructuring of the cytoskeleton to form viral inclusion bodies occur early in the viral infection cycle. Therefore, these would seem good candidates as targets for podophyllotoxin activity. The reported inactivity of podophyllotoxin against an RNA virus [19] may be due to the fact that in this case replication does not occur in the nucleus, negating the need for microtubular involvement in replication. 
Given the data available, we conclude that by either breaking down the microtubular transport system, or by inhibiting the formation of viral inclusion bodies, podophyllotoxin serves to protect the resting cell from HSV-1 infection. It is possible that both of the mechanisms mentioned above rely upon the binding of one or more viral proteins to a microtubular or cytoskeletal structure. By inhibition of this binding, rather than destruction of the cytoskeleton itself, it may be possible to produce less toxic antiviral compounds.

\section{References}

1. Sullivan KF. Structure and utilization of tubulin isotypes. Annu Rev Cell Biol 1988; 4: 687-716.

2. Dustin P (ed). Microtubules, 2nd rev. edn. Berlin, SpringerVerlag. 1984.

3. Carlier MF. Role of nucleotide hydrolysis in the dynamics of actin-filaments and microtubules. Int Rev Cytol 1989; 115: 139-170.

4. Avila J. Microtubule dynamics. FASEB $J$ 1990; 4: 3284-3290.

5. Erickson HP, O'Brien ET. Microtubule dynamic instability and GTP hydrolysis. Annu Rev Biophys Biomol Struct 1992; 21: 145-166.

6. Avila J. Microtubule functions. Life Sci 1992; 50: 327-334.

7. Schulze E, Kirschner M. Dynamic and stable populations of microtubules in cells. $J$ Cell Biol 1987; 104: 277-288.

8. Cassimeris LU, Walker RA, Pryer NK, Salmon ED. Dynamic instability of microtubules. Bioessays 1987; 7: 149-154.

9. Bibor-hardy V, Bernard $M$, Simard R. Nuclear matrix modifications at different stages of infection by herpes-simplex virus type 1. J Gen Virol 1985; 66: 1095-1103.

10. Bibor-hardy V, Pouchelet M, St-Pierre E. Herzberg M, Simard $R$. The nuclear matrix is involved in herpes-simplex virogenesis. Virology 1982; 121: 296-306.

11. Quinlan MP, Knipe DM. Nuclear-localization of herpesvirus proteins - potential role for the cellular framework. Mol Cell Biol 1983; 3: 315-324.

12. Ciampor $F$. The role of cytoskeleton and nuclear matrix in virus replication. Acta Virol 1988; 32: 168-189.

13. Knipe DM. Virus-host-cell interactions. In: Fields BN, Knipe DM (eds) Fundamental virology, 2nd edn. New York, Raven. 1991: 267-290.
14. Luduena RF, Anderson WH, Prasad V et al. Interactions of vinblastine and maytansine with tubulin. Ann NY Acad Sci 1986; 466: 718-732.

15. Schilstra MJ, Martin SR, Bayley PM. The effect of podophyllotoxin on microtubule dynamics. $J$ Biol Chem 1989; 264: 8827-8834.

16. Markkanen T, Makinen ML, Maunuksela E, Himanen P. Podophyllotoxin lignans under experimental antiviral research. Drug Exp Clin Res 1981; 7: 711-718.

17. Bedows E, Hatfield GM. An investigation of the antiviral activity of Podophyllum peltatum. J Nat Prod 1982; 45: 725 729.

18. Macrae WD, Towers GHN. Biological activities of lignans Phytochem 1984; 23: 1207-1220.

19. Macrae WD, Hudson JB, Towers GHN. The antiviral action of lignans. Planta Med 1989; 55: 531-535.

20. Farnsworth NR, Svoboda GH, Blomster RN. Antiviral activity of selected Catharanthus alkaloids. J Pharm Sci 1968; 57: 2174-2175.

21. Spendlove RS, Lenette EH, Chin JN, Knight CO. Effect of antimitotic agents on intracellular reovirus antigen. Cancer Res 1964; 24: 1826-1833.

22. Richardson $C D$, Vance DE. The effect of colchicine and dubucaine on the morphogenesis of Semliki Forest Virus. $J$ Biol Chem 1978; 253: 4584-4589.

23. Satake M, Luftig RB. Association of murine leukemia viral proteins with the cytoskeleton. J Cell Biol 1981; 91: 326a.

24. Seif R. Factors which disorganize microtubules or microfilaments increase the frequency of cell transformation by polyoma virus. J Virol 1980; 36: 421-428.

25. Knipe DM, Senechek D, Rice SA, Smith JL. Stages in the nuclear-association of the herpes-simplex virus transcriptional activator protein ICP4. J Virol 1987; 61: 276-284.

26. Jackson DE, Dewick PM. Aryltetralin lignans from Podophyllum hexandrum and Podophyllum peltatum. Phytochem 1984; 23: 1147-1152.

27. Freshney RJ (ed). Culture of animal cells. New York, WilleyLiss. 1989: 253-255.

28. Takeuchi H, Baba M, Shigeta S. An application of tetrazolium (MTT) colorimetric assay for the screening of antiherpes simplex virus compounds. J Virol Methods 1991; 33 61-71.

29. De Clercq E, Desgranges C, Herdewijn $P$ et al. Synthesis and antiviral activity of (E)-5-(2-Bromovinyl)uracil and (E)-5-(2Bromovinyl)uridine. $J$ Med Chem 1986; 29: 213-217.

30. Kelleher JK. Tubulin binding affinities of podophyllotoxin and colchicine analogues. Mol Pharmacol 1977; 13: 232-241.

31. Gaskin F, Cantor CR, Shelanski ML. Turbidimetric studies of the in vitro assembly and disassembly of porcine neurotubules. J Mol Biol 1974; 89: 737-755. 